\title{
Study on the Relationship between Medical Students' Worry Level, Coping Style and Sleep
}

\author{
Zhenzhen Cai ${ }^{1,}$ Ming Jin ${ }^{1}$ Tiantian Zu ${ }^{1}$ Panpan Yang ${ }^{1 \mathrm{~d}}$ \\ ${ }^{1}$ Mental Health School of Qiqihar Medical College, Qiqihar ,161006,China \\ dAuthor for correspondence dyangpp008@163.com
}

Fund projects:"Chinese Undergraduate Innovative Entrepreneur Training Program", the national key project;project number:201611230016; The 14th college students extracurricular scientific research subject of Qiqihar Medical college.

Keywords: Medical students, sleep quality, yuan concerns, ways

Abstract. Objective: To explore the relationship between sleep quality and mata-worry level and coping style of medical students. Methods: The Pittsburgh Sleep Quality Index Scale (PSQI), mata-worry scale and coping style scale were used to conduct random sampling survey among Qiqihar medical students. Results: (I) Daytime dysfunction (36.8\%); followed by sleep time (26.4\%) sleep disorders (14.5\%) and sleep quality (14.5\%) mainly affect the medical students sleep. (II) sex on sleep time, the reasons for anxiety, coping styles have an impact; (III)grade of sleep quality, sleep time, sleep time, sleep disorders, problem-solving, help have an impact. There is no interaction between gender and grade. $(\mathrm{P}<0.01)$. Sleep duration was positively correlated with uncertainty tolerance $(\mathrm{p}<0.01)$. The reason of hypnotic drug and anxiety was significantly higher than that of anxiety $(p<0.01)$. (4) Sleep quality, daytime dysfunction, Negative correlation $(p<0.01)$. The time of falling asleep was positively correlated with fantasy and withdrawal $(p<0.01)$. Conclusion: The level of anxiety and coping style have effect on the sleep quality of medical students. By changing the irrational cognition and negative coping style, breaking the vicious cycle caused by meta-worry, can effectively improve the quality of sleep in medical college students.

\section{Objects and methods}

(I)Subjects

Make the undergraduate students in Qiqihar Medical University as the study, the College of 400 different grades of medical students to conduct a questionnaire survey.

(II) Methods

(1) Sampling method Random

Sampling, randomly selected students in the freshman sophomore three or three grades of 400 medical students.

(2) Survey methods

Sleep quality, sleep time, sleep time, sleep efficiency, sleep disorders, the use of hypnotic drugs and daytime dysfunction 7 dimensions [1]; each dimension is divided into three dimensions: Score by 0 to 3: Poor for 3 points, worse for 2 points, preferably 1 point, very good for 0 points, different dimensions and sums counted PSCI total score, score range is $0-21$. The total score of score $<8$ was interpreted as a better sleep, total score $\geqslant 8$ was interpreted as poor sleep, the lower the scale score, that sleep better.

The mata-worry scale was compiled by Mike $\mathrm{H}$ et al., Which was translated by Qin Zibing. The scale consisted of 47 items, including the reason of meta-worry and indefinite tolerance. Likert ratings were scored as 1-5 points from five different levels of "very nonconforming" - "very well matched" [2].

Coping Style Questionnaire Using the questionnaire written by Xiao and others in our country, the reliability and validity of the questionnaires in the adolescent group were good. The reliability 
index of the questionnaire was tested by the stability coefficient. The confidence coefficient of 0.62 to 0.72 indicates that the questionnaire is reliable [3].

The study used a questionnaire survey method, through the analysis of the results of the questionnaire analysis of coping style, meta-concerns on the impact of sleep quality.

(3)Quality control: Investigation team members for the professional training of psychiatry students, by the guidance of professional teachers. Questionnaires before the release of the emphasis on the importance of the questionnaire, the messenger was taken seriously questionnaire, the quality of the questionnaire to ensure that. Questionnaire data entry, after repeated confirmation calibration, data with reference value.

(4) Statistical analysis:Using EPi Data 3.0 to build the database, using spss 17.0 analysis of variance, rank correlation analysis. $\mathrm{P}<0.05$ difference was significant.

\section{Results}

(I) Basic information

A total of 400 valid questionnaires were collected from 400 medical students of Qiqihar Medical College from the random sampling method. The total effective rate was $95 \%$. Among the valid questionnaires, 114 were freshmen (46 boys and 68 girls), 133 were sophomores ( 54 boys and 79 girls) and 133 were junior ( 65 boys and 68 girls).

(II)Medical students sleep

(36.8\%) accounted for the highest proportion of sleep quality among the students in Qiqihar Medical College, followed by sleep time (26.4\%), sleep disorders (14.5\%) and sleep quality (14.5\%). The results are shown in Table 1.

\begin{tabular}{ccccc}
\multicolumn{5}{c}{ Table 1 Medical students sleep } \\
\hline & 0 & \multicolumn{3}{c}{ level \% } \\
\cline { 2 - 5 } & 0 & 1 & 2 & 3 \\
\hline Sleep quality & 27.2 & 58.3 & 13.0 & 1.5 \\
Sleeping time & 33.0 & 40.6 & 16.3 & 0.1 \\
Sleep time & 75.6 & 21.8 & 1.7 & 7.8 \\
Sleep efficiency & 82.6 & 7.5 & 2.1 & 0.7 \\
Sleep disorders & 25.2 & 60.3 & 13.8 & 0.8 \\
Hypnotics & 90.9 & 6.8 & 1.5 & 10.5 \\
Daytime & 17.6 & 46.5 & 26.3 & \\
Obstruction & & & & \\
\hline
\end{tabular}

(III) Sleep quality index and mata-worry, coping style of gender, grade characteristics

Sleep time, the reasons for concern, help, solve the problem of gender differences in four areas. The mean scores of the boys were higher than those of the girls, but the boys had better performance than the girls in the sleep quality, the sleep time, the sleep time, the sleep time, the sleep time, the anxiety reason, the help factor, Sleep disorders, daytime dysfunction, several factors on the different grades there are differences. After the average test, the score of freshman is significantly higher than that of sophomore and sophomore, but for solving the problem, the rationalization of the two factors is better than that of freshman. The results are shown in Table 2. 
Table 2 sleep quality index and meta-worry, coping style sex, grade characteristics

\begin{tabular}{|c|c|c|c|c|c|c|c|c|c|c|c|c|c|}
\hline & \multicolumn{2}{|c|}{ men } & \multicolumn{2}{|c|}{ women } & \multicolumn{3}{|c|}{ Freshman } & \multicolumn{2}{|c|}{ Sophomore } & \multicolumn{2}{|c|}{ unior } & \multirow{2}{*}{$\mathrm{F}$} & \multirow{2}{*}{$\begin{array}{l}\mathrm{F} \quad \text { sex } \\
\times \\
\text { grade }\end{array}$} \\
\hline & $\mathrm{M}$ & $\mathrm{SD}$ & $\mathrm{M}$ & $\mathrm{SD}$ & & $\mathrm{M}$ & $\mathrm{SD}$ & $\mathrm{M}$ & $\mathrm{SD}$ & $\mathrm{M}$ & $\mathrm{SD}$ & & \\
\hline Sleep quality & 1.03 & 0.08 & 1.09 & 0.69 & 0.26 & 1.11 & 0.09 & 0.98 & 0.11 & 0.87 & 0.07 & $4.32 *$ & 0.41 \\
\hline Sleeping time & 1.05 & 0.84 & 0.99 & 0.85 & 0.58 & 1.02 & 0.81 & 0.89 & 0.75 & 0.78 & 0.87 & $5.10 *$ & 0.04 \\
\hline Sleep time & 0.79 & 0.64 & 0.49 & 0.51 & $3.71 *$ & 0.79 & 0.60 & 0.76 & 0.76 & 0.69 & 0.66 & $3.67 *$ & 1.31 \\
\hline Sleep efficiency & 0.79 & 1.21 & 0.79 & 0.98 & 0.15 & 0.71 & 1.23 & 0.78 & 0.83 & 0.45 & 0.72 & 0.32 & 0.69 \\
\hline Sleep disorder & 1.03 & 0.53 & 1.04 & 0.51 & 0.32 & 1.12 & 0.53 & 0.78 & 0.59 & 0.78 & 0.52 & $4.21 *$ & 1.05 \\
\hline Hypnotics & 0.05 & 0.48 & 0.04 & 0.29 & 0.56 & 0.15 & 0.38 & 0.05 & 0.21 & 0.01 & 0.45 & 0.05 & 0.23 \\
\hline Daytime Barrier & 1.53 & 0.92 & 1.59 & 0.89 & 1.32 & 1.56 & 0.91 & 1.38 & 0.94 & 1.38 & 0.95 & $3.72 *$ & 0.92 \\
\hline Reasons for concern & 42.38 & 1.70 & 40.29 & 2.95 & $3.41 *$ & 38.65 & 4.64 & 41.76 & 3.25 & 43.89 & 2.40 & 0.78 & 0.49 \\
\hline $\begin{array}{c}\text { Uncertainty of } \\
\text { tolerance }\end{array}$ & 55.76 & 2.48 & 59.82 & 3.84 & 0.05 & 55.20 & 1.37 & 56.84 & 4.84 & 61.33 & 3.57 & 0.62 & 0.06 \\
\hline Solve the problem & 0.71 & 0.14 & 0.69 & 0.18 & $4.32 *$ & 0.69 & 0.16 & 0.71 & 0.14 & 0.71 & 0.14 & 0.92 & 1.01 \\
\hline Self-accusation & 0.29 & 0.23 & 0.33 & 0.25 & 0.92 & 0.32 & 0.24 & 0.28 & 0.23 & 0.28 & 0.23 & 0.65 & 0.25 \\
\hline Help & 0.45 & 0.22 & 0.52 & 0.23 & $4.20 *$ & 0.51 & 0.23 & 0.45 & 0.22 & 0.32 & 0.23 & 0.03 & 1.23 \\
\hline Fantasy & 0.45 & 0.19 & 0.48 & 0.19 & 1.17 & 0.45 & 0.17 & 0.41 & 0.19 & 0.40 & 0.17 & 0.41 & 0.31 \\
\hline Retraction & 0.32 & 0.17 & 0.33 & 0.16 & 1.08 & 0.33 & 0.15 & 0.31 & 0.14 & 0.33 & 0.19 & 0.11 & 0.12 \\
\hline Rationalization & 0.32 & 0.20 & 0.28 & 0.16 & 0.27 & 0.29 & 0.21 & 0.30 & 0.16 & 0.33 & 0.21 & 0.09 & 1.06 \\
\hline
\end{tabular}

Note: $* \mathrm{P}<0.05, * * \mathrm{P}<0.01$

(IV)Sleep quality index and meta-worry, the level of correlation analysis of coping style

There was a significant positive correlation between sleep quality, daytime dysfunction and the two factors of reason of worry. Sleep time was positively correlated with uncertainty tolerance, and hypnotic was negatively correlated with the reason of worry. Sleep time, sleep efficiency and sleep disturbance were positively correlated with self - blame. There was a positive correlation between sleep time and help - seeking and fantasy withdrawal. Sleep quality, sleep time and daytime dysfunction were negatively correlated with positive coping styles such as problem solving, seeking help and rationalization. The results are shown in Table 3.

Table 3 Sleep quality index and meta-worry, the level of correlation analysis of coping style 


\begin{tabular}{|c|c|c|c|c|c|c|c|c|c|c|c|c|c|c|c|}
\hline & $\begin{array}{l}\text { Sleep } \\
\text { quality }\end{array}$ & $\begin{array}{l}\text { Sleep } \\
\text { time }\end{array}$ & $\begin{array}{c}\text { Slee } \\
p \\
\text { time }\end{array}$ & $\begin{array}{l}\text { leep } \\
\text { effici } \\
\text { ency }\end{array}$ & $\begin{array}{c}\text { Sleep } \\
\text { disor } \\
\text { der }\end{array}$ & $\begin{array}{l}\text { Hyp } \\
\text { notic } \\
\text { drug } \\
\text { s }\end{array}$ & $\begin{array}{c}\text { Day } \\
\text { disord } \\
\text { er }\end{array}$ & $\begin{array}{l}\text { Con } \\
\text { cern } \\
\text { ed } \\
\text { reas } \\
\text { ons }\end{array}$ & $\begin{array}{c}\text { Un } \\
\text { cer } \\
\text { tai } \\
\mathrm{n} \\
\text { pat } \\
\text { ien } \\
\text { ce }\end{array}$ & $\begin{array}{c}\text { Pro } \\
\text { ble } \\
\mathrm{m} \\
\text { sol } \\
\text { vin } \\
\mathrm{g}\end{array}$ & $\begin{array}{c}\text { Self } \\
\text {-bla } \\
\text { me }\end{array}$ & $\begin{array}{c}\mathrm{Hel} \\
\mathrm{p}\end{array}$ & $\begin{array}{c}\text { Fan } \\
\text { tas } \\
y\end{array}$ & $\begin{array}{l}\text { Ret } \\
\text { reat }\end{array}$ & $\begin{array}{l}\text { Rationalizati } \\
\text { on }\end{array}$ \\
\hline Sleep quality & 1.00 & & & & & & & & & & & & & & \\
\hline Sleeping time & $0.15^{* *}$ & 1.00 & & & & & & & & & & & & & \\
\hline Sleep time & 0.05 & $\begin{array}{c}0.14^{*} \\
*\end{array}$ & 1.00 & & & & & & & & & & & & \\
\hline Sleep efficiency & $0.14 * *$ & $\begin{array}{l}0.17 * \\
*\end{array}$ & $\begin{array}{c}0.16 \\
* *\end{array}$ & 1.00 & & & & & & & & & & & \\
\hline Sleep disorder & $0.16^{* *}$ & $\begin{array}{l}0.14^{*} \\
*\end{array}$ & 0.07 & 0.06 & 1.00 & & & & & & & & & & \\
\hline Hypnotics & -0.04 & -0.02 & $\begin{array}{c}-0.0 \\
1\end{array}$ & -0.05 & 0.04 & 1.00 & & & & & & & & & \\
\hline Day barrier & 0.07 & $\begin{array}{c}0.14 * \\
*\end{array}$ & $\begin{array}{c}0.16 \\
* *\end{array}$ & $\begin{array}{l}0.12 \\
*\end{array}$ & $\begin{array}{l}0.14^{*} \\
*\end{array}$ & $\begin{array}{c}0.11 \\
*\end{array}$ & 1.00 & & & & & & & & \\
\hline Reasons for concern & $0.14^{* *}$ & 0.06 & 0.01 & $\begin{array}{c}0.11 \\
*\end{array}$ & 0.01 & $\begin{array}{l}-0.1 \\
4 * *\end{array}$ & $\begin{array}{c}0.15^{*} \\
*\end{array}$ & 1.00 & & & & & & & \\
\hline $\begin{array}{l}\text { Uncertainty of } \\
\text { tolerance }\end{array}$ & $0.15^{* *}$ & 0.05 & $\begin{array}{c}0.11 \\
*\end{array}$ & 0.08 & 0.03 & 0.07 & $\begin{array}{l}0.16^{*} \\
*\end{array}$ & $\begin{array}{c}0.16 \\
* *\end{array}$ & $\begin{array}{c}1.0 \\
0\end{array}$ & & & & & & \\
\hline Solve a problem & $\begin{array}{c}-0.14^{*} \\
*\end{array}$ & -0.07 & $\begin{array}{l}-0.1 \\
5 * *\end{array}$ & -0.06 & -0.06 & $\begin{array}{c}-0.0 \\
1\end{array}$ & $\begin{array}{l}-0.15 \\
* *\end{array}$ & $\begin{array}{c}-0.0 \\
4\end{array}$ & $\begin{array}{l}-0 . \\
02\end{array}$ & $\begin{array}{c}1.0 \\
0\end{array}$ & & & & & \\
\hline Self-accusation & 0.05 & $\begin{array}{l}0.16^{*} \\
*\end{array}$ & 0.02 & $\begin{array}{c}0.16 \\
* *\end{array}$ & $\begin{array}{l}0.16^{*} \\
*\end{array}$ & $\begin{array}{c}-0.0 \\
6\end{array}$ & 0.02 & $\begin{array}{c}0.14 \\
* *\end{array}$ & $\begin{array}{c}0.0 \\
1\end{array}$ & $\begin{array}{l}0.0 \\
2\end{array}$ & 1.00 & & & & \\
\hline Help & $\begin{array}{c}-0.15^{*} \\
*\end{array}$ & $\begin{array}{l}0.16^{*} \\
*\end{array}$ & $\begin{array}{l}-0.1 \\
6^{* *}\end{array}$ & -0.07 & -0.01 & 0.05 & $\begin{array}{c}-0.14 \\
* *\end{array}$ & $\begin{array}{l}-0.1 \\
5 * *\end{array}$ & $\begin{array}{c}0.0 \\
2\end{array}$ & $\begin{array}{l}0.1 \\
6 * *\end{array}$ & 0.02 & 1.00 & & & \\
\hline Fantasy & 0.08 & $\begin{array}{c}0.15^{*} \\
*\end{array}$ & 0.01 & 0.03 & 0.05 & $\begin{array}{c}-0.0 \\
3\end{array}$ & 0.03 & $\begin{array}{c}0.15 \\
* *\end{array}$ & $\begin{array}{l}0.1 \\
2^{*}\end{array}$ & $\begin{array}{l}-0 . \\
01\end{array}$ & $\begin{array}{c}-0.0 \\
1\end{array}$ & $\begin{array}{l}-0.1 \\
2 *\end{array}$ & $\begin{array}{c}1.0 \\
0\end{array}$ & & \\
\hline Retraction & 0.07 & $\begin{array}{l}0.14^{*} \\
*\end{array}$ & 0.08 & 0.01 & 0.04 & 0.02 & 0.02 & 0.02 & $\begin{array}{c}0.0 \\
3\end{array}$ & $\begin{array}{c}0.0 \\
2\end{array}$ & 0.04 & $\begin{array}{l}-0.1 \\
4 * *\end{array}$ & $\begin{array}{c}0.0 \\
3\end{array}$ & $\begin{array}{c}1.0 \\
0\end{array}$ & \\
\hline
\end{tabular}




$\begin{array}{ccccccccccccccccc}\text { Rationalization } & -0.13^{*} & -0.07 & -0.1 & 0.02 & 0.01 & -0.0 & -0.15 & 0.03 & -0 . & 0.0 & -0.1 & -0.0 & 0.0 & -0.0 & 1.00 \\ & * & & 6 * * & & & 2 & * * & & 12 & 6 & 3 * * & 6 & 2 & 1 & \end{array}$

\section{Note: $* * \mathrm{P}<0.05, * * * \mathrm{P}<0.001$}

\section{Discussion}

(I)Found

(36.8\%) had the largest proportion of sleep problems, followed by sleep time (26.4\%), sleep disorders (14.6\%), and sleep quality (14.5\%) in the sleep problems of Qiqihar medical students. It can be seen that Qiqihar School of Medicine freshman sophomore students sleep is not ideal.

3.2 From the data analysis, medical students sleep time with grade, gender differences,

(II) The principle of combination of routine and regular

From the data analysis, medical students sleep time with grade, gender differences, sophomore, junior students score higher than freshman students.High-grade students are more likely to be addicted to mobile entertainment experiences and have a higher degree of addiction than younger students. In terms of sleep time, there are also gender main effect, male students score higher than female students, may be associated with the boys online obsession led to the occupation of healthy sleep time. Girls in the back, self-blame and other negative coping style and sleep quality, daytime dysfunction and other aspects of performance than boys, boys in positive coping approach than girls get higher scores may be more willing to male students Using positive response measures to improve the negative experience of self. So that the quality of sleep is better than girls. 


\section{(III)Conclusion}

The correlation analysis showed that the subjective sleep status of the medical students was positively related to the negative coping styles such as self-blame and withdrawal, which indicated that the coping style of depression had a negative effect on the sleep status of medical students, Way will lead to unhealthy sleep. The rank correlation analysis also showed that sleep quality and daytime dysfunction were positively correlated with the cause of worry and uncertainty tolerance. At the same time, sleep time is also positively correlated with the factor's tolerance for uncertainty. Indicating that the level of worry about the level of medical students sleep disorders is also a decisive factor. Therefore, the medical profession, compared with other professions than the broader knowledge and more stringent requirements, so as medical students, have a more heavy burden of learning and from the social family of various ideological burden, may increase their Of sleep disorders.

Change the cognitive way to avoid the yuan worry about the adverse cycle is the first condition to solve the sleep problem. Reduce the anxiety level of medical students, increase the attention of low-grade and female population, and guide students to choose the correct and positive coping style to deal with difficulties and failures in learning life, good coping style will help individual positive and optimistic response to various Negative life events alleviate negative emotions and thus enhance the sense of life. And ultimately improve the medical students to help them sleep disorders from the plight of insomnia.

\section{References}

[1] Wang Xiangdong, Wang Xilin, Ma Hong Mental Health Rating Scale Manual (updated edition) [M]. Beijing: China Mental Health Journal, 1999: 375-378.

[2] Qin Zibing, Wang Yingchun, Qi Nanxiang, et al.Psychological Test of Love, Occupation and Personality [M]. Beijing: China Light Industry Press, 2003: 364-370.

[3] Wang Xiangdong, Wang Xilin, Ma Hong. Mental Health Rating Scale [M]. Chinese Mental Health Journal, 1999: 31-35,109-115,122-124 